\title{
C. FinANCIAL MARKET RISK AND Gold INVESTMENT IN AN EMERGING MARKET: THE CASE OF MALAYSIA
}

\author{
Ibrahim H. MANSOR ${ }^{1}$
}

\begin{abstract}
The present paper examines the relation between gold return and stock market return and whether its relation changes in times of consecutive negative market returns for an emerging market, Malaysia. We find a significant positive but low correlation between gold and once-lagged stock returns. Moreover, consecutive negative market returns do not seem to intensify the co-movement between the gold and stock markets as normally documented among national stock markets in times of financial turbulences. Indeed, there is some evidence that the gold market surges when faced with consecutive market declines. Based on these results, there are potential benefits of gold investment during periods of stock market slumps.
\end{abstract}

Keywords: gold investment, market return, correlations, market risk JEL Classification: G10, G11, G14, G15

\section{Introduction}

Over the past decades, the global financial markets have witnessed a string of financial crises, among them including the Mexican peso crisis in 1994, the Asian financial flu in 1997/1998, the Russian crisis in 1998, the Brazilian crisis in 1999, the Argentine financial crisis in 2001/2002 and, most recently, the US subprime crisis in 2007 and the Greece financial crisis in 2009. The mentioning of these crises is likely to conjure up in the mind of many the images of excessive risk in stock market investment and to bring back interest in gold as an alternative investment asset. This interest is well-placed, as gold used to be a standard of value; it is still considered as a store of value and is universally accepted. Moreover, there seems to be a strong belief that gold can provide protection, as a hedge or a safe haven, against this heightened risk in the financial markets. As noted by Baur and McDermott (2010), gold differs from other assets in that it reacts positively to adverse market shocks. As they mention, real gold value reached its historic high roughly in 1980 , when the

\footnotetext{
${ }^{1}$ Department of Economics, Faculty of Economics and Management, University Putra Malaysia, 43400 Serdang UPM Selangor, Malaysia, E-mail: mansorhi@econ.upm.edu.my.
} 
global economy faced the threat of stagflation due to oil crises in 1970s. Likewise, at the time the US subprime crisis intensified in September 2008, gold has responded with a surge in its value (Baur and McDermott, 2010).

Against a backdrop of recurring financial crises and contagion as well as emerging interest in gold, several studies have attempted empirical investigation of gold hedging property. Notable among these studies are recent works by Capie et al. (2005), Hillier et al. (2006), Baur and Lucey (2010) and Baur and McDermott (2010). Capie et al. (2005) investigate an exchange rate hedge of gold using weekly data of gold price and sterling-dollar and yen-dollar exchange rates from January 1971 to February 2004. They find supportive evidence for exchange rate hedging property of gold, although the strength of hedging tends do vary over time. Hillier et al. (2006) assesses the investment role of precious metals, namely gold, platinum and silver for the US market. They note low correlations between these three metals and stock market returns, which suggests diversification benefits of gold investment. Baur and Lucey (2010) examines whether gold is a safe haven, i.e. maintaining its value in times of market stress or turmoil, for the US, the UK and German markets. They document evidence suggesting the ability of gold to hedge against financial risks and to serve as a safe haven in extreme market conditions for these markets.

Most recently, Baur and McDermott (2010) extend the work of Baur and Lucey (2010) to a larger number of markets, which include both major developed and emerging markets. They analyze the relations between gold return and returns of world and emerging market indexes, various regional market indexes, and 13 individual market indexes. Their results demonstrate the ability of gold to provide a hedge and a strong safe haven for the European and US markets. Thus, for the developed markets, gold provides protection against losses during extreme market conditions. As they explain, investors in these markets sell stocks and buy gold when faced with heightened financial risk. By contrast, the emerging markets seem to lack these properties, indicating that investors tend to react differently to adverse shocks in the emerging markets. Namely, they shift the composition of their portfolios by selling shares of emerging markets and seeking shelter in the developed markets, which are viewed to be relatively safe.

In the present paper, we take lead from these studies and examine the investment role of gold for an emerging Asian market, Malaysia. We attempt to contribute to this line of inquiry in several aspects. First, in Baur and McDermott (2010), the investment role of gold for emerging markets is examined by looking at the relation between gold return and emerging market index return and individual market returns of four largest emerging markets - i.e. Brazil, Russian Federation, India and China. We add to their study by looking at a smaller emerging market. Second, while the present study looks at gold investment from an international perspective, we look at the issue from a domestic perspective. All the aforementioned studies employ gold price in US dollar in their analysis. Instead of using the dollar-denominated gold price and converting it into domestic currency unit as in Baur and Lucey (2010), we use the domestic gold price instead. While we acknowledge that the Malaysian gold price may have depended on the global gold price, the use of gold price quoted domestically in ringgit screens out potential confounding effect of exchange rate movement and currency 
Financial Market Risk and Gold Investment

conversion. Finally, we bring out a new empirical perspective in evaluating the investment role of gold. Namely, we examine whether gold maintains its value or its relation with market returns when faced with consecutive negative daily returns.

We focus on Malaysia due to deep interest in gold shown by Malaysian policymakers and academics in the face of 1997/1998 Asian financial crisis. Tun Mahathir Mohamad, the then Prime Minister of Malaysia, voiced interest in this universally accepted asset and proposed the use of gold particularly in international trade settlement (News Strait Times, 2001). A series of international conferences have been organized on the subject of gold and gold Dinar ${ }^{2}$, among them including the International Conference on Stable and Just Monetary System and International Conference on the Gold Dinar in Multilateral Trade in 2002, International Conference on Gold in International Trade in 2003, and International Conference on Gold Dinar Economy in 2007. In July 2001, Malaysia became the $12^{\text {th }}$ country in the world to have its own gold bullion coins through the launching of the gold bullion coins known as Kijang Emas by the Royal Mint Malaysia. This is followed by the issuance of Royal Mint gold Dinar in 2003 and Kelantan State gold Dinar in 2006. While the introduction of these gold coins is to serve primarily as a store of value or an alternative financial asset for investment, the gold investment performance for the case of Malaysia has hardly received any empirical attention. The availability of daily domestic gold bullion price since 2001 provides us an opportunity to examine the investment role of gold from a domestic market perspective and, at the same time, widens the literature on the emerging markets.

The rest of the paper is structured as follows. In the next section, we provide the empirical framework used in the analysis. Section 3 describes the data. Section 4 presents and discusses estimation results. Finally, section 5 concludes with the main findings and some concluding remarks.

\section{The Empirical Framework}

We specify our empirical model using an autoregressive distributed lag model along the line of Capie et al. (2005). Thus, we have

$$
R_{G, t}=\alpha+\rho R_{G, t-1}+\beta_{1} R_{S, t}+\beta_{2} R_{S, t-1}+\varepsilon_{t}
$$

where: $R_{G}$ is the daily return of gold investment and $R_{S}$ is the corresponding return of stock investment. The lagged dependent is included to allow for autocorrelation structure in gold return. Meanwhile, the incorporation of once-lagged stock return is based on our presumption that, in the emerging markets, the transmission of information among markets may take time. That is, the changes in stock return may be impounded into the gold return with lag. The total sensitivity of gold return to stock market fluctuations is based on the sum of stock market coefficients, i.e. $\beta_{1}+\beta_{2}$. If this sum is significantly positive and is far from unit or the model explanatory is close to zero, we may conclude that gold serves as a diversification asset (see also Hillier et

\footnotetext{
${ }^{2}$ Dinar refers to the name of gold coin used in Islamic history. The interest in gold Dinar during the Asian financial crisis is not only limited to its store of value role and its use in international trade settlement but also to the adoption of gold as a payment standard.
} 
al. 2006). Meanwhile, if it is not significant or is significantly negative, then gold investment can provide a hedge against financial market risk (Baur and Lucey, 2010; Baur and McDermott, 2010). We refer to (1) as our basic model.

Based on (1), we ask further whether gold return dynamics remain similar under conditions of consecutive negative market returns. To this end, we adapt the framework used by Nam at el. (2005) in their analysis of stock return asymmetry by modifying (1) as:

$R_{G, t}=\alpha_{0}+\alpha_{1} N m_{t}+\rho R_{G, t-1}+\left(\beta_{10}+\beta_{11} N m_{t}\right) \times R_{S, t}+\left(\beta_{20}+\beta_{21} N m_{t}\right) \times R_{S, t-1}+\varepsilon_{t}$

where: $N m_{t}$ is a dummy variable representing consecutive negative market returns. Five alternative dummies corresponding to days of consecutive negative returns are considered and they are defined as:

$$
\begin{aligned}
& N 0=\left[\begin{array}{ll}
1 & \text { if } R_{S, t}<0 \\
0 & \text { otherwise }
\end{array}\right. \\
& N 1=\left[\begin{array}{ll}
1 & \text { if } R_{S, t}<0, R_{S, t-1}<0 \\
0 & \text { otherwise }
\end{array}\right. \\
& N 4=\left[\begin{array}{ll}
1 & \text { if } R_{S, t}<0, R_{S, t-1}<0, \ldots, R_{S, t-4}<0 \\
0 & \text { otherwise }
\end{array}\right.
\end{aligned}
$$

One should note that we include $\mathrm{Nm}$ as both intercept and interactive dummies. The intercept dummy is intended to capture the level effect of $m+1$ consecutive negative market returns, current return and the returns of last $m$ days, on gold return. Meanwhile, the interactive dummy is to capture the changing relations between stock return and gold return under conditions of consecutive negative market returns, the main interest of the paper. In the paper, we denote these models with alternative definition of dummies respectively as model N0, N1, N2, N3, and N4.

In (2), the sum $\beta_{10}+\beta_{20}$ captures the relation between the two markets under normal market conditions while $\beta_{10}+\beta_{20}+\beta_{11}+\beta_{21}$ measures their relation when the stock market experiences $m+1$ days of consecutive negative returns. Accordingly, the significance of $\beta_{11}$ and $\beta_{21}$ reflects the changing relations between gold return and market return in times of market downturns. If they are significantly positive, then the gold return tends to move in closer tandem to stock market movement, weakening gold investment role as a diversification asset. However, if they are significantly negative, then gold investment is said to provide at least a hedge against financial losses during market downturns. Finally, if they are insignificantly different from 0 , the dynamics of gold return tends to resist the slumps in stock prices and preserves its relation to the stock market regardless of the market conditions. We believe that this perspective that we bring provides a nice complementary empirical exercise to the works of Baur and Lucey (2010) and Baur and McDermott (2010) that look at the relations between the two during extreme market conditions.

In the implementation of (1) and (2), we take note of ample evidence that highfrequency asset returns tend to exhibit leptokurtic property or volatility clustering, the 


\section{Financial Market Risk and Gold Investment}

so-called autoregressive conditional heteroskedasticity $(\mathrm{ARCH})$ effect. In the finance literature, various error distributions have been assumed and variance equation specifications have been suggested. The error distribution is assumed to be distributed according to either the normal distribution $(\mathrm{N})$, t-distribution $(\mathrm{T})$, or generalized error distribution (G). Among the time-varying variance specifications include the generalized autoregressive conditional heteroskedasticity (GARCH), Threshold ARCH (TARCH), and Exponential GARCH (EGARCH). The latter two allow for asymmetric responses of volatility to positive and negative shocks. To avoid arbitrary model selection, we follow Capie et al. (2005) by basing on the maximum of log likelihood as a selection criterion. We find asymmetric volatility specification (TARCH or EGARCH) to best fit the gold return dynamics and generalized error distribution to best describe the error distribution. The suitability of asymmetric volatility modeling for gold return is in conformity with the behavior of other asset returns (Lobo, 2000 and Koutmos et al., 2006).

\section{Data}

We employ 2261 daily observations spanning from August $1^{\text {st }}, 2001$ to March $31^{\text {st }}$, 2010. The beginning date is dictated by data availability of gold bullion price. The selling prices of one troy ounce domestic gold bullion are used to represent domestic gold prices while the Kuala Lumpur composite index is used to represent the aggregate prices of stock market investment. The data on the two prices are sourced from Malaysia's central bank, Bank Negara Malaysia, and Data Stream International, respectively. We compute gold and stock market returns as the first difference of the natural log of the respective series. Table 1 provides the descriptive statistics of the two returns. We also plot these series in level and first-differenced forms in Figure 1.

Both gold and stock prices experience an upward trend over the sample period. While the daily average gold return is relatively higher than the daily average stock market return (i.e. $0.06 \%$ against $0.03 \%$ ), it is more volatile than the market return as reflected by their respective standard deviations. This is accounted by the more extreme positive values of gold return (0.1246) than the stock market return (0.0426). Meanwhile, the extreme negative value of stock market return $(-0.9997)$ is only slightly higher than the corresponding value of gold return $(-0.0782)$. From the plots, we also note marked reduction in stock market prices around years of the Argentine financial crisis in 2001/2002 and of the US subprime crisis in 2007/2008. While the gold return is positively skewed, the market return demonstrates a negative skewness. Both return series are characterized by excess peakness having kurtosis statistics to be substantially higher than 3 . This suggests volatility clustering in the return series, which is apparent in the graphical plots. The Jarque-Bera statistics reported at the bottom of Table 1 soundly rejects the null of normality for both returns. These characteristics in the data seem to justify the use of GARCH-type models for model specification. 
Graphical Plots of Gold and Stock Prices and Returns

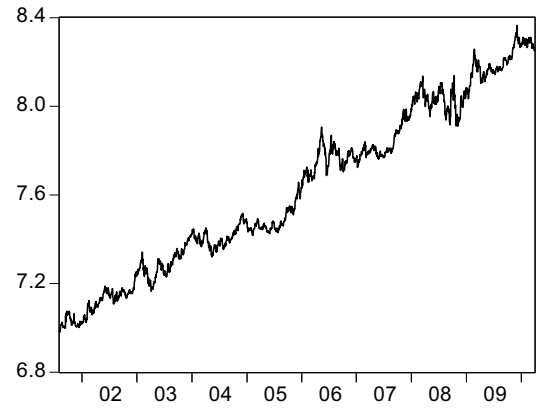

(a) Natural Log of Gold Price

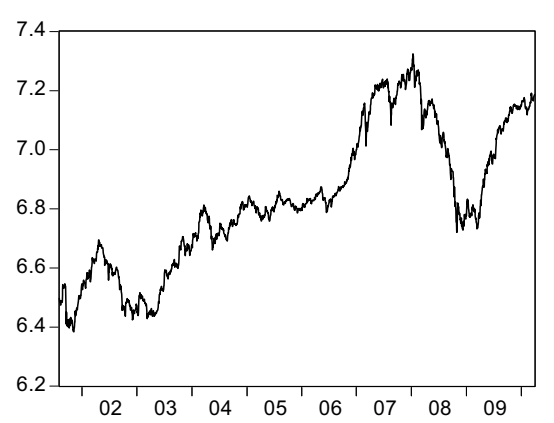

(c) Natural Log of Kuala Lumpur Composite Index

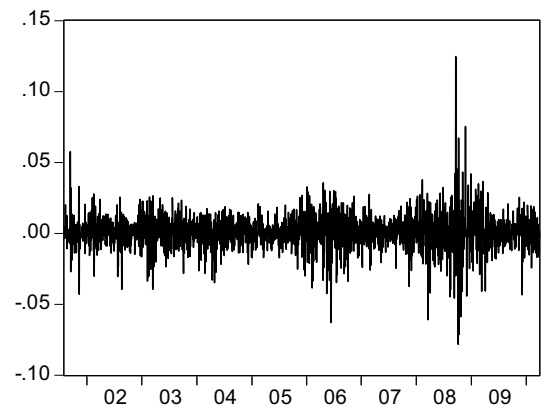

(b) Gold Return

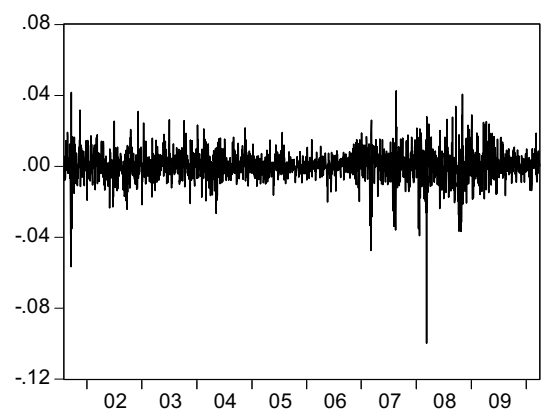

(d) Stock Market Return

Table 1

Descriptive Statistics

\begin{tabular}{|l|c|c|}
\hline & $\Delta G$ & $\Delta S$ \\
\hline Mean & 0.000561 & 0.000305 \\
\hline Median & 0.000000 & $8.72 \mathrm{E}-05$ \\
\hline Maximum & 0.124645 & 0.042587 \\
\hline Minimum & -0.078182 & -0.099785 \\
\hline Std. Dev. & 0.011909 & 0.008518 \\
\hline Skewness & 0.092587 & -0.999659 \\
\hline Kurtosis & 12.58588 & 15.06466 \\
\hline & & 14082.94 \\
\hline Jarque-Bera & 8656.123 & 0.000000 \\
\hline Probability & 0.000000 & \\
\hline & & 2260 \\
\hline Observations & 2260 & \\
\hline
\end{tabular}




\section{Financial Market Risk and Gold Investment}

As a preliminary analysis, we report the cross correlations between $R_{G, t}$ and $R_{S, t}$ for up to 5 lags. With the standard error in the order of 0.021 in absolute value, the correlation of roughly 0.042 and higher suggests significance correlation between the two returns. We note very low and mostly positive correlations between gold return and contemporaneous and lagged stock returns. Among these correlations, only the correlation between gold return and once-lagged stock return is significant. Its correlation is positive, suggesting that the gold market tends to follow the stock market with 1-day lag. The cross-correlations between gold return and lead stock returns indicate the absence of signification correlations. Accordingly, the gold market does not lead the stock market. This preliminary analysis seems to provide a basis for our one-equation empirical approach with no feedback from gold return to stock return and with the inclusion of once-lagged stock return in the mean equation of gold return. As regards to our main interest, it indicates at best the diversification property of gold investment since its noted positive correlation is far from unit. However, this finding is only suggestive and must be subject to a formal analysis, to which we turn next.

Table 2

Estimated Cross-Correlations

\begin{tabular}{|c|c|c|}
\hline $\mathrm{k}$ & $\mathrm{R}_{\mathrm{G}, \mathrm{t}}, \mathrm{R}_{\mathrm{S}, \mathrm{t}-\mathrm{k}}$ & $\mathrm{R}_{\mathrm{G}, \mathrm{t}}, \mathrm{R}_{\mathrm{S}, \mathrm{t}+\mathrm{k}}$ \\
\hline 0 & 0.0032 & 0.0032 \\
\hline 1 & 0.0579 & 0.0240 \\
\hline 2 & -0.0224 & 0.0151 \\
\hline 3 & 0.0127 & 0.0254 \\
\hline 4 & -0.0085 & 0.0258 \\
\hline 5 & 0.0173 & -0.0167 \\
\hline
\end{tabular}

\section{Estimation Results}

This section conducts a formal analysis of gold return and its relation to stock market return as specified in (1) and (2) using GARCH-type models. We experiment with various error distribution assumption and variance specification and choose the one that maximizes the log likelihood. The values of log likelihood functions for alternative models are given in Table 3 . This log likelihood criterion unequivocally suggests the generalized error distribution of error terms. It also suggests either TARCH or EGARCH specification to best describe the variance specification. The TARCH specification is chosen for the basic model, model NO and model N1, while EGARCH specification for the other models. One should note that the differences in the log likelihood values between the two specifications are marginal.

Table 3

Log Likelihood of Alternative GARCH specification

\begin{tabular}{|l|c|c|c|c|c|c|}
\hline \multicolumn{1}{|c|}{ GARCH } & \multicolumn{6}{|c|}{ Model } \\
\hline Specification & Basic & N0 & N1 & N2 & N3 & N4 \\
\hline GARCH-N & 7035.569 & 7035.893 & 7036.291 & 7034.568 & 7031.221 & 7030.379 \\
\hline GARCH-T & 7146.246 & 7146.520 & 7146.26 & 7142.140 & 7138.171 & 7134.302 \\
\hline GARCH-G & 7163.378 & 7165.204 & 7163.645 & 7159.647 & 7156.706 & 7152.533 \\
\hline
\end{tabular}




\begin{tabular}{|l|c|c|c|c|c|c|}
\hline \multicolumn{1}{|c|}{ GARCH } & \multicolumn{6}{c|}{ Model } \\
\hline Specification & Basic & N0 & N1 & N2 & N3 & N4 \\
\hline TGARCH-N & 7046.186 & 7046.458 & 7046.785 & 7045.231 & 7043.397 & 7042.447 \\
\hline TGARCH-T & 7153.767 & 7154.348 & 7153.782 & 7149.472 & 7146.017 & 7141.644 \\
\hline TGARCH-G & $\mathbf{7 1 6 8 . 4 2 1}$ & $\mathbf{7 1 7 0 . 7 0 1}$ & $\mathbf{7 1 6 8 . 7 3 0}$ & 7164.399 & 7162.170 & 7157.886 \\
\hline EGARCH-N & 7026.377 & 7026.710 & 7027.169 & 7031.521 & 7030.436 & 7031.285 \\
\hline EGARCH-T & 7158.247 & 7158.82 & 7158.361 & 7154.147 & 7151.064 & 7146.542 \\
\hline EGARCH-G & 7168.083 & 7170.554 & 7168.641 & $\mathbf{7 1 6 4 . 6 2 8}$ & $\mathbf{7 1 6 3 . 1 0 4}$ & $\mathbf{7 1 5 9 . 0 0 8}$ \\
\hline
\end{tabular}

Estimation of the $\operatorname{TARCH}(1,1)$ model for the basic mean equation yields the following results (numbers in parentheses are $\mathrm{p}$-values):

$$
\begin{aligned}
R_{G, t}= & 0.0004-0.0344 R_{G, t-1}-0.0111 R_{S, t}+0.0502 R_{S, t-1} \\
& (0.016) \quad(0.046) \quad(0.582) \quad(0.014) \\
h_{t}= & 0.0000014+0.0772 \varepsilon_{t-1}^{2}-0.0535 \varepsilon_{t-1}^{2} I_{t-1}+0.9413 h_{t-1} \\
& (0.008) \quad(0.000) \quad(0.003)
\end{aligned}
$$

$\mathrm{N}=2259$, GED Parameter $=1.7025(0.000)$, Log Likelihood $=7168.42$

where: $I_{t}=1$ if $\varepsilon_{t}<0$ and 0 otherwise. The use of TARCH model implies that previous shocks have asymmetric effects on volatility. Since the coefficient of $\varepsilon_{t-1}^{2} l_{t-1}$ is negative, bad news $\left(\varepsilon_{t}<0\right)$ tends to dampen market volatility. In other words, oncelagged positive news $\left(\varepsilon_{t-1}>0\right)$ exerts a greater impact on gold return volatility than the negative news does, which conforms to the finding of Capie et al. (2005). Moreover, gold return volatility tends to be highly persistent, as suggested by the large coefficient of lagged volatility. Turning to our main theme, we note the significance of only oncelagged stock return. This conforms to the correlation structure observed in the previous section. However, its coefficient is small, in the order of 0.05 . Thus, a 10 percentage point reduction in stock returns is associated to the decrease in stock return by 0.50 percentage point on average, and likewise for the stock market increase. One should note that the coefficient of lagged gold return is negative. This suggests that the gold return tends to exhibit a reversal pattern and that the long-run impact on gold return of stock market variations is even smaller.

In order to evaluate the dynamics of gold return during times of consecutive negative market returns, we estimate the chosen GARCH models (Table 3 ) for the consecutive negative returns ranging from 1 day to 5 days (equation 2). The results of estimation are provided in Table 4. One should note from the table that there are no changes in the results for the variance equation. Gold return volatility depends mostly on its past volatility and positive shocks tend to propel higher volatility. In the mean equation, we generally observe no level effect of consecutive negative market returns on gold return except for model 3. Similar to the basic model, we note significant positive coefficient of lagged stock return in all models except one, i.e. model N0. More important, there seems to be no changes in the relations between gold and stock returns in times of consecutive negative market returns. The coefficients of interactive dummies are all indistinguishable from 0 except one, i.e. the N3 model. In the case of 


\section{Financial Market Risk and Gold Investment}

N3 model, the investment role of gold is further enhanced. In responses to four consecutive negative market returns, current and last three-day returns, the gold market tends to move in the opposite direction of stock market slumps. The coefficient of interactive dummy-lagged stock return in the N3 model is significantly negative and its magnitude (in absolute term) is substantially higher than the coefficient of lagged stock return. Thus, there seems to be a movement of the gold market away from downward trend in the stock market.

Table 4

Estimation Results of Extended Models

\begin{tabular}{|c|c|c|c|c|c|}
\hline & \multicolumn{5}{|l|}{ Model } \\
\hline \begin{tabular}{|l|} 
Estimated \\
Coefficients
\end{tabular} & $\begin{array}{l}\text { N0 } \\
\text { (TARCH) }\end{array}$ & $\begin{array}{l}\text { N1 } \\
\text { (TARCH) }\end{array}$ & $\begin{array}{l}\mathrm{N} 2 \\
\text { (EGARCH) }\end{array}$ & \begin{tabular}{|l}
$\mathrm{N} 3$ \\
(EGARCH)
\end{tabular} & $\begin{array}{l}\text { N4 } \\
\text { (EGARCH) }\end{array}$ \\
\hline \multicolumn{6}{|c|}{ Mean Equation } \\
\hline$\alpha_{0}$ & 0.0000 & 0.0003 & 0.0004 & 0.0004 & 0.0004 \\
\hline$\alpha_{1}$ & -0.0007 & -0.0004 & 0.0001 & $-0.0025^{* *}$ & -0.0008 \\
\hline$\rho$ & -0.0315 & -0.0320 & $-0.0341^{\prime \prime}$ & -0.0265 & -0.0284 \\
\hline$\beta_{10}$ & 0.0465 & -0.0054 & -0.0093 & -0.0034 & -0.0036 \\
\hline$\beta_{11}$ & -0.0602 & 0.0263 & 0.0110 & -0.0979 & -0.0146 \\
\hline$\beta_{20}$ & 0.0352 & $0.0545^{\star x}$ & 0.0474 ** & 0.0549 & $0.0507^{* *}$ \\
\hline$\beta_{21}$ & 0.0254 & -0.0114 & 0.0150 & $-0.2243^{* *}$ & -0.2640 \\
\hline \multicolumn{6}{|c|}{ Variance Equation } \\
\hline$\theta_{0}$ & 0.000001 & 0.000001 & -0.1156 & -0.1064 & $-0.1261^{*}$ \\
\hline$\theta_{1}$ & $0.0809^{* * \pi}$ & $0.0776^{* \pi *}$ & $0.0858^{* * *}$ & $0.0830^{* * *}$ & $0.0923^{* *}$ \\
\hline$\theta_{2}$ & -0.0575 & -0.0539 & 0.0595 & $0.0603^{\prime \prime}$ & 0.0592 \\
\hline$\theta_{3}$ & $0.9402^{* * x}$ & 0.9410 & $0.9942^{\star \star \star x}$ & 0.9950 & 0.9936 \\
\hline
\end{tabular}

Notes: the estimated models are:

Mean Equation:

$R_{G, t}=\alpha_{0}+\alpha_{1} N m_{t}+\rho R_{G, t-1}+\left(\beta_{10}+\beta_{11} N m_{t}\right) \times R_{S, t}+\left(\beta_{20}+\beta_{21} N m_{t}\right) \times R_{S, t-1}+\varepsilon_{t}$ Variance Equations:

TARCH: $h_{t}=\theta_{0}+\theta_{1} \varepsilon_{t-1}^{2}+\theta_{2} \varepsilon_{t-1}^{2} \times I_{t-1}+\theta_{3} h_{t-1}$

GARCH: $\log h_{t}=\theta_{0}+\theta_{1}\left|\frac{\varepsilon_{t-1}}{\sqrt{h_{t-1}}}\right|+\theta_{2} \frac{\varepsilon_{t-1}}{h_{t-1}}+\theta_{3} \log h_{t-1}$

${ }^{*},{ }^{* *}$, and ${ }^{* * *}$ denote significance at $10 \%, 5 \%$ and $1 \%$ respectively.

The evidence that we uncover, thus, supports strong resistance of the gold market to stock market downturns. This is in sharp contrast to the well-documented finding that national stock markets tend to have strong co-movements during times of market 
decline and turmoil, which limit potential diversification benefit across national stock markets. The heightened reaction of domestic stock markets to downturns in other markets have been documented by Pagan and Soydemir (2001) and Bahng and Shin (2003) for several emerging markets. Moreover, the financial crises are noted to propagate shocks more strongly through the contagion or domino effect (Dornbusch et al., 2000; Hasman and Samartin, 2008; Markwat et al., 2009). Thus, a flight to other markets for shelter during times of financial crises may not help. In the case of gold investment, its diversification benefits are not restrained in times of market downturns. Indeed, there is some evidence that the stock market may surge in value when the stock market posts a negative trend.

\section{Conclusion}

A series of financial crises that erupted in different parts of the world and their accompanying excessive risk have raised serious concern over investment in stock markets and are likely to bring back interest in gold as an alternative investment asset. In light of this, we examine the relation between gold and stock returns and investigate whether it changes during times of consecutive negative market returns for an emerging market, Malaysia. Applying GARCH-type models to daily gold and stock returns over the period August 2001 to March 2010, we uncover evidence indicating significant positive relation between gold return and once-lagged stock return. However, the coefficient of the once-lagged stock return in gold return equation is small and far from unit. We further note that their relation has not strengthened during times of consecutive days of market declines. To the contrary, we find some evidence that gold return tends to break from its positive relation with stock market return following four consecutive stock market returns. These findings are in sharp contrast to the observed strong co-movements among national stock markets in periods of market downturns, which are attributed to contagion or domino effect.

Based on these results, we incline to suggest the favorable property of gold as an investment asset for the Malaysian emerging market. At least, gold provides a diversification benefit to investors in the Malaysian market. The domestic Malaysian gold market tends to have resistance to heightened risk in the stock market as it preserves its low positive relation with stock market variations regardless of the market conditions. At best, with evidence pointing to the negative relation between gold return and stock market return after four consecutive negative market returns, gold tends to possess a hedging property in times of market declines. In short, our results seem to support the initiative by Malaysia in introducing various gold coins, namely Kijang Emas, Royal Mint gold Dinar and Kelantan State gold Dinar, as a vehicle for preserving wealth in the midst of recurring financial turbulences during the present time. 
Financial Market Risk and Gold Investment

\section{References}

Bahng, J.S. and Shin, S.-M., 2003. Do Stock Price Indices Respond Asymmetrically? Evidence from China, Japan, and South Korea. Journal of Asian Economics, 14, pp.541-563.

Baur, D.G. and Lucey, B.M., 2010. Is Gold a Hedge or a Safe Haven? An Analysis of Stocks, Bonds, and Gold. The Financial Review, 45, pp.217-229.

Baur, D.G. and McDermott, T.K. 2010. Is Gold a Safe Haven? International Evidence. Journal of Banking and Finance, 34, pp.1886-1898.

Dornbusch, R., Park, Y., and Claessens, S., 2000. Contagion: How it Spreads and How it can be Stopped. World Bank Research Observer, 15, pp.177197.

Capie, F., Mills, T.C. and Wood, G., 2005. Gold as a Hedge against the Dollar. Journal of International Financial Markets, Institutions and Money, 15, 343-352.

Hasman, A., and Samartin, M., 2008. Information Acquisition and Financial Contagion. Journal of Banking and Finance, 32, pp.2136-2147.

Hillier, D., Draper, P. and Faff, R., 2006. Do Precious Metals Shine? An Investment Perspective. Financial Analysts Journal, 62(2), pp.98-106.

Koutmos, G. and Martin, A.D., 2003. Asymmetric Exchange Rate Exposure: Theory and Evidence," International Journal of Money and Finance, 22(3), pp.365-383.

Lobo, B.J., 2000. Asymmetric Effects of Interest Rate Changes on Stock Prices. The Financial Review, 35, pp.125-144.

Markwat, T., Kole, E., and van Dijk, D., 2009. Contagion as a Domino Effect in Global Stock Markets. Journal of Banking and Finance, 33, pp.1996-2012.

Nam, K., Washer, K.M., and Chu, Q.C., 2005. Asymmetric Return Dynamics and Technical Trading Strategies. Journal of Banking and Finance, 29, pp.391-418.

News Strait Times, 2001. Standardize Practices in Islamic Banking, June 26.

Pagan, J.A. and Soydemir, G.A., 2001. Response Asymmetries in the Latin American Equity Markets. International Review of Financial Analysis, 10, pp.175-185. 